\title{
Quality improvement of doctors' shift-change handover in neuro-critical care
}

\author{
M N Lyons, ${ }^{1}$ T D A Standley, ${ }^{2}$ A K Gupta ${ }^{1,3,4}$
}

\begin{abstract}
${ }^{1}$ Postgraduate Medical Centre, The Clinical School, Cambridge University Hospitals NHS Foundation Trust, Addenbrooke's Hospital, Cambridge, UK

${ }^{2}$ University Division of Anaesthesia, Addenbrooke's Hospital, Cambridge, UK ${ }^{3}$ Neurosciences Critical Care Unit, Cambridge, UK ${ }^{4}$ Addenbrooke's Simulation Centre, Cambridge, UK
\end{abstract}

\section{Correspondence to}

Dr Melinda Lyons, National Patient Safety Agency, 4-8 Maple Street, London W1T 5HD, UK;

melinda_lyons@hotmail.com

Accepted 5 October 2009 Published Online First 27 April 2010

\author{
ABSTRACT \\ Background Clinical handover is a necessary process for \\ the continuation of safe patient care; however, \\ deficiencies in the handover process can introduce error. \\ While the number of handover studies increases, few \\ have validated implemented improvements with \\ repeated audit.
}

Objective To improve the morning handover round on a busy critical care unit and assess sustainability of improvement through repeated audit.

Design/Methods A quality improvement process based on prospective observational assessment of the doctor's shift-change handover was carried out, assessing the content of clinical information and effects of distractions, location and timing. The effect of a training session for the junior doctors with the introduction of a standardised handover protocol was assessed.

Results The content of clinical information improved after the training session with introduction of a standardised protocol, but returned to baseline with a new cohort of untrained doctors. Distractions were associated with increased handover times for individual patients and for total handover time. Overall, handover time was shortest in the coffee room compared with ward and lecture theatre handovers. Individual patient handover time was positively correlated with clinical content scores. Four indices of critical illness all positively correlated with increased handover time. Conclusions Early specific training is vital for quality clinical handover. Distractions during handover cause inefficiency and can adversely affect information transfer. Changing handover location according to local environment can yield improved efficiency, structure and ease of management. Adequate time must be allocated for clinical handover especially when dealing with very sick and complex patients.

Clinical handover between shift changes is a necessary process to ensure seamless continuity of patient care. However, deficiencies in the handover process can introduce error. The accurate transfer of a necessary amount of clinical information to allow the continuation of safe care and, in addition, bring fresh intelligence to clinical problems, requires an efficient, clear and comprehensive system of communication.

Despite awareness that handover systems were inadequate as long ago as 1996 in the UK, ${ }^{1}$ it has taken several years for action to be taken, prompting the production of guidelines for handover. $^{2}$

Despite the large number of handover studies conducted in the past two decades (table 1 ; refs $^{3-53}$ ), few have carried out audits with quantitative measures, implementing improvements and vali- dating these with repeated audit. While academic and practical quality improvement agendas rarely overlap, ${ }^{3}$ Davidoff and Batalden ${ }^{54}$ have provided guidelines for reporting quality improvement work to encourage its publication, and to increase completeness and transparency. Additionally, Hearnshaw et a $t^{55}$ have clarified guidance for using audit as a quality improvement tool.

We wished to improve the morning handover round on our 21-bed Neurosciences Critical Care Unit (NCCU), a busy unit with a bed occupancy rate of approximately $90 \%$, caring for neurosurgical/neurology and general patients requiring intensive care. Our specific aim was to improve the quality of the whole process. We felt that a goodquality handover would use the most appropriate setting, where the environment enhanced information transfer in addition to maximising the time utilised so that pertinent and complete clinical information was presented and discussed without unnecessary elaboration, leading to the initiation of necessary clinical action. However, some internal tensions exist in these criteria-for example, the environment should reduce distractions but not useful discussion, and time efficiency should not lead to omissions in the clinical information presented. In initiating this quality improvement work, we were conscious of the complex nature of handover; however, we hoped that by following a planned approach, we would discover a way to improve the handover process in our unit, in addition to understanding more of the intricacies of the process itself.

\section{SETTING}

The round is large, typically including the nighttime junior doctor and a sizeable group of oncoming staff. This amounts to more than 20 people on most mornings, primarily led by the NCCU consultant for the day, with neurosurgical consultants taking individual interest in certain patients. The original structure was a walk round of neurosurgical patients first before handover of the general patients between NCCU staff members only. The round is the only time when all interested clinicians are present to receive up-to-date information as the evening handover only involves the late-shift junior doctor and their oncoming counterpart. Before this project, the round normally took approximately $40 \mathrm{~min}$ to complete and functions mainly as a "business round" where information is presented, condition is verified and plans are made. While this is planned to start promptly at 8:00, frequently this would be delayed by the absence of key team members. Family members may be present at bedside and input information 
Table 1 Summary of literature

\begin{tabular}{|c|c|c|}
\hline Article (first author) & Methodology & Findings and conclusions \\
\hline Gandhi ${ }^{3}$ & Case study of errors & $\begin{array}{l}\text { Multiple handoffs can lead to diffused responsibility, necessitating clear lines of } \\
\text { responsibility }\end{array}$ \\
\hline Vidyarthi $^{4}$ & Case and commentary & $\begin{array}{l}\text { Discontinuity in hospitals is inevitable, especially with shifts. "Sign-out" should } \\
\text { be standardised }\end{array}$ \\
\hline Horn $^{5}$ & Survey of UK anaesthesia handover practice & $\begin{array}{l}\text { Little formalisation, differing opinions on key considerations. Guidelines, } \\
\text { standardisation and documentation would help }\end{array}$ \\
\hline Kerr $^{6}$ & $\begin{array}{l}\text { Observation and interviews of nurse handover-sociotechnical } \\
\text { perspective }\end{array}$ & Handover is complex, with social and educational aspects \\
\hline Manias $^{7}$ & Ethnographic study of nursing handover & $\begin{array}{l}\text { Identified practices within handover, including tyranny of busyness, tyranny of } \\
\text { tidiness and need to identify sense of finality }\end{array}$ \\
\hline Lally $^{8}$ & Observational study & $\begin{array}{l}\text { Team building was a stronger theme than transfer of patient information during } \\
\text { nursing handover }\end{array}$ \\
\hline Sherlock $^{9}$ & Observational study & $\begin{array}{l}\text { Handover is complex, with variable quality of information, lack of organisation } \\
\text { and standardisation. Teaching and documentation are required }\end{array}$ \\
\hline Skeoch $^{10}$ & Commentary & Issues raised in handover of neonates from transport \\
\hline Sexton $^{11}$ & Audio-taping of nursing handovers & $\begin{array}{l}84.6 \% \text { of information discussed could be found elsewhere. Streamlining could } \\
\text { improve quality and reduce time }\end{array}$ \\
\hline Thakore $^{12}$ & $\begin{array}{l}\text { Questionnaires for those involved in handover } \\
\text { of patients from ambulance to resuscitation }\end{array}$ & Identified a need for training to improve quality \\
\hline Patterson ${ }^{13}$ & $\begin{array}{l}\text { Observation study to identify strategies for handover in } \\
\text { different industries }\end{array}$ & $\begin{array}{l}\text { Different strategies used in different industries have different consequences for } \\
\text { failure }\end{array}$ \\
\hline Leonard $^{14}$ & Commentary & There is a need to standardise communication in clinical practice \\
\hline Bomba $^{15}$ & Observation, questionnaire and interviews & $\begin{array}{l}\text { Doctors' handover was unstructured, informal and error prone. Formalisation } \\
\text { and computerisation would help }\end{array}$ \\
\hline Nemeth $^{16}$ & Observation and conversation analysis & $\begin{array}{l}\text { Expertise depends on the ability to prioritise information; formal training in } \\
\text { handover may benefit patients and clinicians }\end{array}$ \\
\hline Coiera $^{17}$ & Observation in emergency department & $\begin{array}{l}\text { There is a need for training in communication. Interruptions disrupt memory } \\
\text { processes. Most information exchanges are informal }\end{array}$ \\
\hline Alvarez $^{18}$ & Observation in intensive care unit & $\begin{array}{l}\text { There is a high burden of interruptions on communications in the intensive care } \\
\text { context }\end{array}$ \\
\hline Berens $^{19}$ & Review & $\begin{array}{l}\text { Noise levels in the paediatric intensive care unit are sufficiently high to be of } \\
\text { concern }\end{array}$ \\
\hline Barenfanger $^{20}$ & Interventional behavioural study in laboratory context & Introducing "readback" into communication procedures reduces errors \\
\hline $\begin{array}{l}\text { Australian Council for } \\
\text { Safety and Quality in } \\
\text { Healthcare }^{21}\end{array}$ & $\begin{array}{l}\text { Review on system, organisational culture and individual factors } \\
\text { influencing handover }\end{array}$ & There is a need for protocols and training in handover \\
\hline Solet $^{22}$ & Observational study of four different junior doctor handovers & $\begin{array}{l}\text { Four major barriers to an effective hand-off were (1) physical setting, (2) social } \\
\text { setting, (3) language barriers and (4) communication barriers. Precise, } \\
\text { unambiguous, face-to-face communication is best. Standardisation and } \\
\text { education are required }\end{array}$ \\
\hline Hopkinson ${ }^{23}$ & Phenomenological study (semistructured interviews) & $\begin{array}{l}\text { Handover is a forum for expressing opinions and feelings as well as patient } \\
\text { information }\end{array}$ \\
\hline Strange ${ }^{24}$ & Ethnographic observational study & Ritual of handover serves valuable psychological, social and protective functions \\
\hline Odell ${ }^{25}$ & $\begin{array}{l}\text { Review of communication theory applied to nursing shift } \\
\text { handover }\end{array}$ & $\begin{array}{l}\text { Handover should be constantly reviewed to maintain efficiency. Theory can help } \\
\text { develop staff and the handover process }\end{array}$ \\
\hline Anwari $^{26}$ & Observation to develop a scale to assess quality of handover & $\begin{array}{l}\text { Scale incorporated quality of verbal information, patient condition, professional } \\
\text { behaviour and nurse's satisfaction with handover }\end{array}$ \\
\hline McKenna ${ }^{27}$ & Description of process for change & Handover times were successfully reduced, allowing more efficient working \\
\hline Kelly ${ }^{28}$ & Questionnaires + description of process for change & Changing handover location can be achieved by careful management \\
\hline Watkins $^{29}$ & Description of process for change & Changing handover location can be achieved by careful management \\
\hline Williams $^{30}$ & Description of process for change & Changing handover location can be achieved by careful management \\
\hline Miller $^{31}$ & Review article & $\begin{array}{l}\text { Regular reviews, written guidelines and preprepared handover sheets help } \\
\text { maintain efficiency }\end{array}$ \\
\hline $0^{\prime}$ Connell ${ }^{32}$ & $\begin{array}{l}\text { Observational study }+ \text { semistructured interviews (five nursing } \\
\text { acute care setting handovers) }\end{array}$ & No particular style was superior. Handover helps to debrief, clarify and educate \\
\hline Kennedy ${ }^{33}$ & Observational study+interviews & Nursing care plans can replace oral handovers and are more efficient \\
\hline Wallum ${ }^{34}$ & Description of process for change & Nursing care plans can replace oral handovers \\
\hline Meißner ${ }^{35}$ & Questionnaire survey & Handover frequently causes irritation, often due to organisational problems \\
\hline Borowitz ${ }^{36}$ & Prospective questionnaire survey & Important information is often missed \\
\hline McCann ${ }^{37}$ & Questionnaire survey & $\begin{array}{l}\text { Clinical problems were attributed to poor handover. Set location, standardised } \\
\text { handover sheet and training were recommended }\end{array}$ \\
\hline $\mathrm{Ye}^{38}$ & Observational study+questionnaire survey & $\begin{array}{l}\text { Important information is often missed, leading to adverse effects. } \\
\text { Standardisation, use of IT, feedback, quality assurance and education were } \\
\text { suggested }\end{array}$ \\
\hline Bhabra $^{39}$ & Observational study & Printed handout sheets improved retention of information \\
\hline Catchpole $^{40}$ & Observational study & $\begin{array}{l}\text { Introduction of handover protocol (based on motorsport/aviation) reduced } \\
\text { technical errors, omissions and handover time }\end{array}$ \\
\hline Fenton $^{41}$ & Audit & Use of a handover guide may improve structure and information content \\
\hline
\end{tabular}


Table 1 Continued

\begin{tabular}{|c|c|c|}
\hline Article (first author) & Methodology & Findings and conclusions \\
\hline Ferran $^{42}$ & Audit & Use of a proforma increased quantity of information transferred \\
\hline Pothier $^{43}$ & Observational study & Printed handout sheets improved retention of information \\
\hline Wayne $^{44}$ & Observational study, focus group discussion+various surveys & $\begin{array}{l}\text { Simplification and standardisation of handoff instrument led to increased } \\
\text { accuracy, completeness and reduced tasks transferred }\end{array}$ \\
\hline Talbot $^{45}$ & Observational study & $\begin{array}{l}\text { Structuring verbal handover did not improve information retention by receiving } \\
\text { staff }\end{array}$ \\
\hline Singh $^{46}$ & Study of closed malpractice claims & Handoff problems are associated with medical errors involving trainees \\
\hline Wilson $^{47}$ & Technical report & A clinical handover appliance can support safe handover \\
\hline Hertzum $^{48}$ & Questionnaire study, observational study+interviews & $\begin{array}{l}\text { Use of an electronic patient record increased clarity about work tasks and } \\
\text { reduced omissions at handover }\end{array}$ \\
\hline Wong $^{49}$ & Case study & $\begin{array}{l}\text { End-users must be involved in the development of electronic support tools for } \\
\text { handover }\end{array}$ \\
\hline Chaboyer $^{50}$ & $\begin{array}{l}\text { Quality improvement project (location change, practice } \\
\text { guideline and competency standard) }\end{array}$ & $\begin{array}{l}\text { Quality improvement agenda for handover improves safety, efficiency, } \\
\text { teamwork and senior support }\end{array}$ \\
\hline Kassean $^{51}$ & Description of process for change & Changing handover location can be achieved by careful management \\
\hline Wilson 52 & Review & Assessing feasibility of IT tools for improving handover \\
\hline Bruce $^{53}$ & Experience reporting, qualitative interviews & Difficult or "non-ideal" handovers characterised by complicated care situation \\
\hline
\end{tabular}

on occasion; however, they are rarely involved in decisionmaking. Only a minority of patients were able to participate in the round while it took place on the ward, the rest being too ill.

\section{METHODS}

The project was planned according to human factors and clinical audit principles. Initial data on the handover process were collected through semistructured interviews performed by a human factors expert (ML). The six NCCU consultants (the most senior clinicians on the unit medical staff) provided this information on the current practice of handover and how this deviated from their expectations of the ideal process. From these interviews, two checklists (for "human factors" (see Appendix A) and clinical content) were prepared to assess the morning handover round in a repeatable fashion. The clinical content was defined on the basis that "if an item was mentioned, even briefly, then this was judged as covered". Using these, a clinical score was calculated by giving one mark (or credit) for each of the seven clinically relevant information items: name, age, diagnosis, overall management goals, important developments overnight/ in the previous $24 \mathrm{~h}$, present problems and problems anticipated in the next $24 \mathrm{~h}$. Distractions were noted on a human factors checklist as occurring events that were viewed as "potentially causing distraction".

The checklists were used to audit the handover in the NCCU for 10 mornings selected opportunistically over a 1-month period (baseline group). This also included timing the handover of individual patients, delays between patients and the length of the whole session.

These initial 10 sessions took place in two locations, as the normal practice of bedside handover had to be stopped after three sessions because of an outbreak of Acinetobacter. The handover then took place in the unit coffee room for the remaining seven sessions.

The authors then undertook a single educational session drawing on the literature review, the audit and the consultants' views. The junior doctors were involved in a facilitated brainstorming exercise to support the development of a protocol (see figure 1) for handover, for their own use. The protocol headings were introduced into the daily handover sheet, prepared by the night-shift junior for the oncoming staff.

A re-audit of 10 mornings within the next month was then undertaken while the educated team of junior doctors was still working on the unit (post-training group), which also coincided with a further change of location, to a small lecture theatre just outside the unit. A final audit of 10 sessions took place when the post-training group had left the unit, to identify if the new process had been passed onto the next group of junior doctors (no-training group). The same observers were used for all stages.

To investigate any correlation between clinical scores/handover times and validated critical illness scoring systems, the Intensive Care National Audit and Research Centre (ICNARC) data (APACHE2 score, APACHE2 mortality prediction, APACHE3 score and MPM 24 mortality prediction) were compared for all patients handed over during the project.

The overall plan and execution of the study is given in figure 2 .

\section{RESULTS}

\section{Timing}

Timing data were collected by each observer, which showed strong inter-rater reliability (Pearson's $r=0.998, p<0.001$ ). Timing results for the handover of individual patients, whole handover sessions and gaps between individual patient handovers are shown in table 1.

The differences in timing for "handover of each patient" over the three phases were not significant $\left(\chi^{2}=2.97, \mathrm{df}=2\right.$, Kruskal-Wallis $=0.23)$. However, there was a significant difference associated with location, as the coffee room was quicker $\left(\chi^{2}=18.02, \mathrm{df}=2\right.$, Kruskal-Wallis $\left.<0.001\right)$.

The timing for the whole handover session is shown in table 1; the Kruskal-Wallis test showed no significant difference by group $\left(\chi^{2}=1.81, \quad \mathrm{df}=2, \quad\right.$ Kruskal-Wallis $\left.=0.40\right)$ or location $\left(\chi^{2}=3.75, \mathrm{df}=2\right.$, Kruskal-Wallis=0.15), although the coffee room location was tangibly shorter in practice.

The timing of gaps between each patient handover was significantly different from one phase to the next $\left(\chi^{2}=128.05\right.$, $\mathrm{df}=2$, Kruskal - Wallis $=0.001)$. The differences between all the groups were also significant (baseline group/post-training group: Mann-Whitney $U=10,079.5, p<0.001$; post-training group/notraining group: Mann-Whitney $U=8708, p<0.001)$. There was also a significant difference in gaps between locations $\left(\chi^{2} 121.51\right.$, $\mathrm{df}=2$, Kruskal-Wallis $<0.001$ ).

\section{Clinical content}

The differences in clinical content over the phases were significant $\left(\chi^{2}=21.2, \mathrm{df}=2\right.$, Kruskal-Wallis $\left.<0.001\right)$. The differences 


\section{HANDOVER PROTOCOL}

Ensure all handover participants are present and listening! (Explain handover process to any new participants)

For each patient:

BED NUMBER

NAME

AGE

DIAGNOSIS: Presenting complaint / condition (1 sentence)

HISTORY:

Brief history of presentation

Date of admission to hospital / NCCU

Pathway to NCCU

Reason for current admission to hospital / NCCU

Previous relevant medical problems

Previous interventions

\section{LAST 24 HOURS / OVERNIGHT}

Significant events / change

Results of investigations received

Information from specialties

Active interventions undertaken

Discussions with family

\section{CURRENT ISSUES}

Present problems

Indicate investigations expected

NEXT 24 HOURS

Outstanding issues

Plans for transfer

Investigations required

Planned therapy / surgery

Specialties to be contacted

Discussions with family

CONFIRM INFORMATION HAS BEEN RECEIVED AND OFFER OPPORTUNITY TO ASK

QUESTIONS - "anything else?"

\section{CONFIRM END OF PATIENT HANDOVER}

For the unit:

BED ALLOCATION

PATIENT TRANSFERS

PATIENTS EXPECTED

Figure 1 Handover protocol.

were found between the baseline group and the post-training group (Mann-Whitney $U=12759, p<0.001$ ), and the posttraining group and the no-training group ((Mann-Whitney $\mathrm{U}=15$ 168.5, $\mathrm{p}<0.001)$, but not between the baseline group and the no-training group (Mann-Whitney $U=16077, p=0.77$ ).

\begin{tabular}{|c|c|c|c|c|}
\hline \multirow{2}{*}{$\begin{array}{l}\text { Interviews } \\
\text { with } \\
\text { consultants }\end{array}$} & Baseline group & \multirow{2}{*}{$\begin{array}{c}\text { Interviews } \\
\text { with junior } \\
\text { doctors }\end{array}$} & \multirow{2}{*}{$\begin{array}{c}\begin{array}{c}\text { Post training } \\
\text { group }\end{array} \\
10 \text { mornings } \\
\end{array}$} & \multirow{2}{*}{$\begin{array}{c}\begin{array}{c}\text { No training } \\
\text { group }\end{array} \\
10 \text { mornings }\end{array}$} \\
\hline & 10 mornings & & & \\
\hline & Ward & Coffee room & \multicolumn{2}{|c|}{ Lecture theatre } \\
\hline & $\begin{array}{c}3 \\
\text { mornings }\end{array}$ & 8 mornings & \multicolumn{2}{|c|}{19 mornings } \\
\hline
\end{tabular}

Figure 2 Study protocol.
For location, this was also significant $\left(\chi^{2}=12.63, \mathrm{df}=2\right.$, Kruskal-Wallis $<0.002)$, with differences between ward and coffee room (Mann-Whitney $U=2620, p<0.002$ ), and ward and lecture theatre (Mann-Whitney $U=7108.0, p<0.001$ ), but not the coffee room and lecture theatre (Mann-Whitney $U=25207$, $\mathrm{p}<0.988)$.

Overall, there is a significant correlation between clinical content score and handover time (Pearson $r=0.17, p<0.01$, twotailed).

There were no significant correlations between ICNARC scores and the clinical score (two-tailed significances of $r=0.43$, $0.74,0.98$ and 0.62 for APACHE2 score, APACHE2 mortality prediction, APACHE3 score and MPM 24, respectively). Correlations between ICNARC scores and patient handover time are shown in table 2 .

\section{Distractions}

Examining the range of distractions, the correlations between handover time and distractions are shown in table 3. Looking at the distractions in relation to clinical content score, there were significant relationships as shown in table 4.

Further details on the statistical information can be obtained from the corresponding author.

\section{Context}

Weaknesses in the handover clinical content and distractions from the two environments were evaluated once the baseline group had been audited. Results were discussed with the NCCU consultants with a view on instigating change. The outcome was a set of local recommendations. First was keeping the handover round off the ward, initially in the unit coffee room and then into the lecture theatre; second, there was a need for a training session for the junior doctors; third, a protocol-driven format was developed; last, management of distractions was performed.

\section{DISCUSSION}

\section{Size and location}

There must be a trade-off of the advantages and disadvantages of each environment. The length of the gaps between patient presentations was substantially longer on the ward because of the time taken moving from one patient to the next. However, clinical content was lower on the ward, implying that the change in location off the ward made an improvement in information transfer, perhaps because of the change in distractions. The findings with ward-based handover round could easily be likened to rounds of similar size where a major factor in failure of information transfer is the number of people involved. When assessing these rounds, the observers were inevitably on the periphery, making it difficult to hear the central participants against competing noise.

The changes in location allowed a number of lessons to be learnt concerning handover practice. The ward had the advantages of allowing doctors to see and speak to the patient, family members and attending nurse, and to consult patient notes. The coffee room allowed for rapid handover but did not allow radiological viewing. The introduction of this in the lecture theatre increased handover time in a beneficial way, promoting clinical discussion. The low transfer time between patients in the coffee room and the lecture theatre helped to make the round more efficient. The pattern of interruptions changed between locations, with less conversation off the round in the coffee room and lecture theatre. The use of these locations also preserved round structure better. Additionally, the risk of 
Table 2 Handover times (seconds) for individual patients, whole handover session times (minutes), delay in overall start times (minutes), time gaps (seconds) between patient handovers, and clinical content scores with respect to group and location

\begin{tabular}{|c|c|c|}
\hline $\begin{array}{l}\text { Handover times (seconds) for individual } \\
\text { patients }\end{array}$ & Mean (SD) & $\mathbf{n}$ \\
\hline $\begin{array}{l}\text { Baseline group } \\
\text { Post-training group } \\
\text { No-training group }\end{array}$ & $\begin{array}{l}99(61) \\
115(80) \\
116(92)\end{array}$ & $\begin{array}{l}166 \\
197 \\
197\end{array}$ \\
\hline $\begin{array}{l}\text { Ward } \\
\text { Coffee room } \\
\text { Lecture theatre }\end{array}$ & $\begin{array}{l}120(64) \\
87(54) \\
118(88)\end{array}$ & $\begin{array}{l}53 \\
133 \\
374\end{array}$ \\
\hline $\begin{array}{l}\text { Whole handover session times } \\
\text { (minutes) }\end{array}$ & Mean (SD) & $\mathrm{n}$ \\
\hline $\begin{array}{l}\text { Baseline group } \\
\text { Post-training group } \\
\text { No-training group }\end{array}$ & $\begin{array}{l}36.6(11.6) \\
43.0(13.2) \\
41.6(13.5)\end{array}$ & $\begin{array}{l}10 \\
10 \\
10\end{array}$ \\
\hline $\begin{array}{l}\text { Ward } \\
\text { Coffee room } \\
\text { Lecture theatre }\end{array}$ & $\begin{array}{l}46.6(15.3) \\
31.7(6.9) \\
43.1(12.9)\end{array}$ & $\begin{array}{l}3 \\
8 \\
19\end{array}$ \\
\hline $\begin{array}{l}\text { Delay in start of handover session } \\
\text { (seconds) }\end{array}$ & Mean (SD) & $\mathbf{n}$ \\
\hline $\begin{array}{l}\text { Baseline group } \\
\text { Post-training group } \\
\text { No-training group }\end{array}$ & $\begin{array}{l}328(156.3) \\
230(126.7) \\
332(146.8)\end{array}$ & $\begin{array}{l}10 \\
10 \\
10\end{array}$ \\
\hline $\begin{array}{l}\text { Ward } \\
\text { Coffee room } \\
\text { Lecture theatre }\end{array}$ & $\begin{array}{l}334(101.3) \\
309(174.6) \\
285(145.8)\end{array}$ & $\begin{array}{l}3 \\
8 \\
19\end{array}$ \\
\hline $\begin{array}{l}\text { Time gaps (seconds) between patient } \\
\text { handovers }\end{array}$ & Mean (SD) & $\mathbf{n}$ \\
\hline $\begin{array}{l}\text { Baseline group } \\
\text { Post-training group } \\
\text { No-training group }\end{array}$ & $\begin{array}{l}12.0(28.7) \\
8.6(38.0) \\
4.8(21.5)\end{array}$ & $\begin{array}{l}156 \\
187 \\
187\end{array}$ \\
\hline $\begin{array}{l}\text { Ward } \\
\text { Coffee room } \\
\text { Lecture theatre }\end{array}$ & $\begin{array}{l}20.7(34.9) \\
8.5(28.4) \\
6.4(30.1)\end{array}$ & $\begin{array}{l}50 \\
125 \\
355\end{array}$ \\
\hline Clinical content scores & Mean (SD) & $\mathbf{n}$ \\
\hline $\begin{array}{l}\text { Baseline group } \\
\text { Post-training group } \\
\text { No-training group }\end{array}$ & $\begin{array}{l}5.91(1.15) \\
6.38(0.79) \\
6.0(1.0)\end{array}$ & $\begin{array}{l}166 \\
197 \\
197\end{array}$ \\
\hline $\begin{array}{l}\text { Ward } \\
\text { Coffee room } \\
\text { Lecture theatre }\end{array}$ & $\begin{array}{l}5.51(1.35) \\
6.15(0.94) \\
6.17(0.93)\end{array}$ & $\begin{array}{l}53 \\
133 \\
374\end{array}$ \\
\hline
\end{tabular}

infection from a large group walking around the unit was negated. Moving the round from the bedside to the lecture theatre represents the best environment for handover to take place, given the improvements in efficiency, clarity and ease of management.

Table 3 Correlation between Intensive Care National Audit and Research Centre data and patient handover time

\begin{tabular}{llc}
\hline & & Patient handover time \\
\hline APACHE2 score & Pearson correlation & 0.083 \\
& Significance (two-tailed) & 0.057 \\
& $\mathrm{n}$ & 525 \\
APACHE2 mortality & Pearson correlation & $0.151^{*}$ \\
& Significance (two-tailed) & 0.001 \\
& $\mathrm{n}$ & 524 \\
APACHE3 score & Pearson correlation & 0.080 \\
& Significance (two-tailed) & 0.063 \\
MPM 24 & $\mathrm{n}$ & 540 \\
& Pearson correlation & $0.099 \dagger$ \\
& Significance (two-tailed) & 0.026 \\
& $\mathrm{n}$ & 502
\end{tabular}

*Correlation is significant at the 0.01 level (two-tailed).

†Correlation is significant at the 0.05 level (two-tailed).
Table 4 Pearson correlations between distractions and handover time (individual and grouped)

\begin{tabular}{|c|c|c|}
\hline $\begin{array}{l}\text { Distractions/extra tasks } \\
\text { involved }\end{array}$ & $\begin{array}{l}\text { Correlation with } \\
\text { patient handover } \\
\text { time and individual } \\
\text { distractions }\end{array}$ & $\begin{array}{l}\text { Correlation between } \\
\text { number of distractions } \\
\text { by type and whole } \\
\text { session time }\end{array}$ \\
\hline $\begin{array}{l}\text { Background conversation } \\
\text { between people who are } \\
\text { involved in the handover }\end{array}$ & $0.39 *$ & $0.59 *$ \\
\hline $\begin{array}{l}\text { Background conversation } \\
\text { between people who are not } \\
\text { involved in the handover }\end{array}$ & -0.01 & 0.03 \\
\hline Doors opening & $0.26^{*}$ & 0.23 \\
\hline $\begin{array}{l}\text { Staff from outside the handover } \\
\text { talking to those who are }\end{array}$ & 0.06 & -0.1 \\
\hline $\begin{array}{l}\text { People walking through the } \\
\text { handover }\end{array}$ & 0.05 & -0.26 \\
\hline Phone ringing near the handover & 0.04 & 0.26 \\
\hline $\begin{array}{l}\text { Phone conversation occurring near } \\
\text { the handover }\end{array}$ & 0.03 & 0.05 \\
\hline $\begin{array}{l}\text { Mobile phone call involving } \\
\text { someone who was involved in the } \\
\text { handover }\end{array}$ & $0.37^{*}$ & $0.54^{*}$ \\
\hline $\begin{array}{l}\text { Bleep going off during the } \\
\text { handover }\end{array}$ & $0.31^{*}$ & $0.4^{*}$ \\
\hline Other alarm & 0.05 & 0.08 \\
\hline TV noise & -0.03 & -0.12 \\
\hline Current patient interrupting & -0.02 & 0.07 \\
\hline Other patient interrupting & 0.01 & 0.07 \\
\hline $\begin{array}{l}\text { A patient's family member } \\
\text { interrupting }\end{array}$ & 0.02 & 0.06 \\
\hline $\begin{array}{l}\text { People making coffee near the } \\
\text { handover }\end{array}$ & 0.03 & -0.18 \\
\hline $\begin{array}{l}\text { People washing up near the } \\
\text { handover }\end{array}$ & 0.02 & -0.18 \\
\hline $\begin{array}{l}\text { Computer noises near the } \\
\text { handover }\end{array}$ & -0.01 & -0.3 \\
\hline $\begin{array}{l}\text { Clinical-related noises (suction } \\
\text { noises) }\end{array}$ & 0.05 & 0.29 \\
\hline $\begin{array}{l}\text { Non-clinical-related noise (ice- } \\
\text { making machine) }\end{array}$ & $0.09 \dagger$ & 0.14 \\
\hline Patient examination & -0.04 & 0.78 \\
\hline Patient communication & -0.04 & 0.21 \\
\hline$x$ Ray viewing & $0.24^{*}$ & 0.36 \\
\hline Total distractions & $0.45^{*}$ & $0.59 *$ \\
\hline
\end{tabular}

\section{Timing}

There was a marked decrease in individual patient handover time and whole-session time in the coffee room. This wholesession time saving equates to at least an hour and a half over the course of a week; however, the extra time taken in the lecture theatre allowed the viewing of radiological investigations, prompting increased, richer clinical discussion.

\section{Training}

The change in clinical score between the baseline group and the post-training group was not sustained with the no-training group, suggesting that the educational session was the key aspect to improving the quality of handover. These data emphasise the need for education in handover practice at the start of the job. While this finding may seem intuitive, its importance cannot be overemphasised.

\section{Correlations to indices of critical illness}

There was no significant correlation between the ICNARC data and the clinical score, possibly reflecting the design of the clinical scoring scale used. Longer handover times were associated with 
Table 5 Pearson correlation between distractions and clinical content score

\begin{tabular}{lc}
\hline & $\begin{array}{c}\text { Correlation between } \\
\text { clinical score of patient } \\
\text { handover and presence of } \\
\text { individual distractions }\end{array}$ \\
\hline Distractions/extra tasks involved & 0.02 \\
\hline Background conversation between people & \\
who are involved in the handover & $-0.09 \dagger$ \\
Background conversation between people & \\
who are not involved in the handover & 0.08 \\
Doors opening & -0.02 \\
Staff from outside the handover talking to & \\
those who are & 0.02 \\
People walking through the handover & 0.004 \\
Phone ringing near the handover & 0.03 \\
Phone conversation occurring near the & \\
handover & 0.06 \\
Mobile phone call involving someone who & \\
was involved in the handover & 0.02 \\
Bleep going off during the handover & -0.06 \\
Other alarm & -0.04 \\
TV noise & $-0.13^{*}$ \\
Current patient interrupting & -0.05 \\
Other patient interrupting & $-0.13^{*}$ \\
A patient's family member interrupting & 0.05 \\
People making coffee near the handover & -0.01 \\
People washing up near the handover & 0.02 \\
Computer noises near the handover & -0.05 \\
Clinical-related noises (suction noises) & 0.04 \\
Non-clinical-related noise (ice-making & \\
machine) & 0.04 \\
Patient examination & $0.12^{*}$ \\
Patient communication & -0.02 \\
$x$ Ray viewing & 0.02 \\
Total distractions & \\
\hline
\end{tabular}

*Correlation is significant at the 0.01 level (two-tailed).

tCorrelation is significant at the 0.05 level (two-tailed).

higher clinical scores. More interestingly, the ICNARC data were universally correlated with handover time, with two scales (APACHE2 mortality prediction and MPM 24) that achieved statistical significance, most likely linked to the complexity of such patients' clinical histories. In the division of resources, of which handover time is one, correct time allocation is surely a marker of quality.

\section{Distractions}

The overall pattern of distractions correlated with the handover time, for individual patients and the whole session. Results relating to background conversation, mobile phones and bleeps with regard to handover time strongly suggest that direct interruptions cause loss of time and must be avoided for efficiency and quality. Several aspects were seen to negatively correlate with clinical score (table 4). A clinician communicating with a patient showed a positive correlation, indicating that, at least in this context, this was a proactive action to ensure correct information rather than an interruption. Many of the distractions listed in tables 3 and 4 are easy to view as having a negative impact.

\section{Limitations}

There were several limitations to this work. There is no guarantee that the checklists are reliable for use by other observers, with the clinical score being quantitative, rather than qualitative, reflecting clinical quality. The study was not blinded and the observers may have "seen and recorded" an improvement that they expected.
Also, there may have been "observer effects", where the trained junior doctors performed better once the presence of the assessors and their purpose were revealed. The role of patients and family members was not included in the study. The standard deviations are often high and thus statistical power is limited, and the large influence of extraneous factors, such as type of clinical environment, experience, culture of leadership, technology and local policies, cannot be underestimated. Common sense should be applied to interpretation of these data.

\section{CONCLUSION}

This experience has been significant as a hypothesis-generating study on ensuring quality improvement in handover, with substantial learning from a variety of sources being brought together in practice to improve quality. While an organised structure for protocol contributed to improvement, this study demonstrates the substantial influence of handover training, which ideally should be introduced as a vital part of education early in junior doctor postings. Distractions during handovers cause inefficiency and adversely affect information transfer. They must be managed to an absolute minimum. Changing handover location according to local environment can yield improved efficiency, handover structure and ease of management. Lastly, the relationship between time taken and clinical quality is not well understood; at each extreme, there are risks of lengthy meandering that adds no clinical benefit or working with time constraints that are too restricted to cover the necessary clinical issues. Adequate time must be allocated for clinical handover especially when dealing with very sick and complex patients.

Most importantly, it is intended that this article be used as a guide for a process of quality improvement that identifies solutions consistent with local needs, rather than as a recommendation of the solutions identified within this local context. One generic recommendation would certainly be to instil the need for a "living improvement process" and ensure that the process can continue to improve in the absence of specific project-driven goals. The handover process should incorporate a means of reminding staff that they may initiate change at any opportunity. This itself is an artefact of a safe culture, empowering staff to control any distractions, including those created by the handover participants.

Funding Addenbrooke's Charitable Trust, Box 126, Addenbrooke's Hospital, Hills Road, Cambridge CB2 000, UK.

Competing interests None.

Provenance and peer review Not commissioned; externally peer reviewed

\section{REFERENCES}

1. Roughton VJ, Severs MP. The junior doctor handover: current practices and future expectations. J R Coll Physicians Lond 1996;30:213-14.

2. Junior Doctors' Committee Safe Handover: Safe Patients. Guidance on clinical handover for clinicians and managers. NHS Modernisation Agency, National Patient Safety Agency. London: British Medical Association, 2004. http://www.bma.org.uk/ library medicine/ (accessed Jan 2006).

3. Gandhi TK. Fumbled handoffs: one dropped ball after another. Ann Intern Med 2005:142:352-8

4. Vidyarthi A. Fumbled handoff: missed communication between teams, discussant. AHRO Web M\&M. http://www.webmm.ahrq.gov March 2004.

5. Horn J, Bell MD, Moss E. Handover of responsibility for the anaesthetised patient opinion and practice. Anaesthesia 2004;59:658-63.

6. Kerr MP. A qualitative study of shift handover practice and function from a sociotechnical perspective. J Adv Nurs 2002;37:125-34.

7. Manias E, Street $A$. The handover: uncovering the hidden practices of nurses. Intensive Crit Care Nurs 2000:16:373-83.

8. Lally S. An investigation into the functions of nurses' communication at the intershift handover. J Nurs Manag 1999;7:29-36.

9. Sherlock C. The patient handover: a study of its form, function and efficiency. Nurs Stand 1995;9:33-6. 
10. Skeoch CH, Booth P. Medical care during transport. Semin Neonatol 1999; 4:281-7.

11. Sexton A, Chan C, Elliott $M$, et al. Nursing handovers: do we really need them? J Nurs Manag 2004;12:37-42.

12. Thakore S, Morrison W. A survey of the perceived quality of patient handover by ambulance staff in the resuscitation room. Emerg Med J 2001:18:293-6.

13. Patterson ES, Roth EM, Woods DD, et al. Handoff strategies in settings with high consequences for failure: lessons for health care operations. Int J Qual Health Care 2004:16:125-32.

14. Leonard M, Graham S, Bonacum D. The human factor: the critical importance of effective teamwork and communication in providing safe care. Qual Saf Health Care 2004;13:85-90.

15. Bomba DT, Prakash R. A description of handover processes in an Australian public hospital. Aust Health Rev 2005;29:68-79.

16. Nemeth CP, O'Connor M, Nunnally $\mathrm{M}$, et al. Distributed cognition: how hand-off communications actually works. Anesthesiology 2005;103:A1289.

17. Coiera EW, Jayasuriya RA, Hardy J, et al. Communication loads on clinical staff in the emergency department. Med J Aust 2006;176:415-18.

18. Alvarez G, Coiera E. Interruptive communication patterns in the intensive care unit ward round. Int J Med Inf 2005:74:791-6.

19. Berens RJ. Noise in the pediatric intensive care unit. J Intensive Care Med 1999;14:118-29.

20. Barenfanger J, Sautter RL, Lang DL, et al. Improving patient safety by repeating (read-back) telephone reports of critical information. Am J Clin Pathol 2004; 121:901-3.

21. Australian Council for Safety and Quality in Healthcare Clinical Handover and Patient Safety Literature Review Report. Australian Resource Centre for Healthcare Innovations, March 2005, ISBN: 0642826544

22. Solet DJ, Norvell JM, Rutan GH, et al. Lost in translation: challenges and opportunities in physician-to-physician communication during patient handoffs. Acad Med 2005;80:1094-9.

23. Hopkinson JB. The hidden benefit: the supportive function of the nursing handover for qualified nurses caring for dying people in hospital. J Clin Nurs 2002:11:168-75.

24. Strange F. Handover: an ethnographic study of ritual in nursing practice. Intensive Crit Care Nurs 1996:12:106-12.

25. Odell A. Communication theory and the shift handover report. $\mathrm{Br} \mathrm{J}$ Nurs 1996;5:1323-6

26. Anwari JS. Quality of handover to the postanaesthesia care unit nurse. Anaesthesia 2002;57:488-93.

27. McKenna L, Walsh K. Changing handover practices: one private hospital's experiences. Int J Nurs Pract 1997;3:128-32.

28. Kelly M. Change from an office-based to a walk-around handover system. Nurs Times 2005;101:34-5

29. Watkins S. Introducing bedside handover reports. Prof Nurse 1997:12:270-3.

30. Williams AJ. Managing change in the nursing handover. Nurs Stand 1998;12:39-42.

31. Miller C. Ensuring continuing care: styles and efficiency of the handover process Aust J Adv Nurs 1998;16:23-7.

32. O'Connell B, Penney W. Challenging the handover ritual. Recommendations for research and practice. Collegian 2001;8:14-18.

33. Kennedy J. An evaluation of non-verbal handover. Prof Nurse 1999;14:391-4.

34. Wallum R. Using care plans to replace the handover. Nurs Stand 1995:9:24-6.

35. Meißner A, Hasselhorn H, Estryn-Behar M, et al. Nurses perception of shift handovers in Europe-results from the European nurses' early exit study. J Adv Nurs 2006 57:535-42.

36. Borowitz SM, Waggoner-Fountatin LA, Bass EJ, et al. Adequacy of information transferred at resident sign-out (in-hospital handover of care): a prospective study. Qual Saf Health Care 2008;17:6-10.

37. McCann L, McHardy K, Child S. Passing the buck: clinical handovers at a tertiary hospital. N Z Med J 2007;120:U2778.

38. Ye K, Taylor DM, Knott JC, et al. Handover in the emergency department: deficiencies and adverse events. Emerg Med Australas 2007:19:433-41.

39. Bhabra G, MacKeith S, Monteiro P, et al. An experimental comparison of handover methods. Ann R Coll Surg Engl 2007;89:298-300.

40. Catchpole K, De Leval MR, McEwan A, et al. Patient handover from surgery to intensive care: using Formula 1 pit-stop and aviation models to improve safety and quality. Paediatr Anaesth 2007;17:470-78.

41. Fenton W. Developing a guide to improve the quality of nurse's handover. Nurs Older People 2006;18:32-6.

42. Ferran NA, Metcalfe AJ, O'Doherty D. Standardised proformas improve patient handover: audit of trauma handover practice. Patient Saf Surg 2008:2:24.
43. Pothier D, Monteiro P, Mooktiar M, et al. Pilot study to show the loss of important data in nursing handover. Br J Nurs 2005;14:1090-3.

44. Wayne JD, Tyagi R, Reinhardt G, et al. Simple standardised patient handoff system that increases accuracy and completeness. J Surg Educ 2008:65: 476-85

45. Talbot R, Bleetman A. Retention of information by emergency department staff at ambulance handover: do standardised approaches work? Emerg Med $J$ 2007:24:539-42

46. Singh $\mathbf{H}$, Thomas EJ, Petersen LA, et al. Medical errors involving trainees. A study of closed malpractice claims from 5 insurers. Arch Intern Med 2007;167:2030-6.

47. Wilson S, Fone J, Galliers J. Clinical Handover Appliance (CHA): a prototype design ACE project technical report ACE/TR3/N1. 18/11/2004

48. Hertzum M, Simonsen J. Positive effects of electronic patient records on three clinical activities. Int J Med Inf 2008;77:809-17.

49. Wong MC, Turner P, Yee KC. Socio-cultural issues and patient safety: a case-study into the development of an electronic support tool for clinical handover. Stud Health Technol Inform 2007;130:279-89.

50. Chaboyer W, McMurray A, Johnson J, et al. Bedside handover: quality improvement strategy to "Transform care at the bedside". J Nurs Care Qual 2009;24:136-42

51. Kassean HK, Jagoo ZB. Managing change in the nursing handover from traditional to bedside handover - a case study from Mauritius. BMC Nurs 2005:4:1.

52. Wilson S, Galliers J, Fone J. Medical handover: a study and implications for information technology. Florence, Italy: Proc. Healthcare Systems, Ergonomics and Patient Safety (HEPS), 2005

53. Bruce K, Suserud B. The handover process and triage of ambulance-borne patients: the experiences of emergency nurses. Nurs Crit Care 2005;10 201-9.

54. Davidoff F, Batalan P. Toward stronger evidence on quality improvement draft publication guidelines: the beginning of a consensus project. Qual Saf Health Care 2005; 14:319-25.

55. Hearnshaw HM, Harker RM, Cheater FM, et al. Are audits wasting resources by measuring the wrong things? A survey of methods used to select audit review criteria. Qual Saf Health Care 2003:12:24-8.

\section{APPENDIX A}

\section{HUMAN FACTORS CHECKLIST}

Who initiates/lead the handover?

Use of handover notes/protocol

Use of readback with handover?

Delay in providing information

Use of patient notes

View $x$ rays

Initiate communication with current patient

Current patient interrupts

Other patient interrupts

Patient relative/carer interrupts

Patient assessed during handover

Active intervention on patient

Doors opening/closing

Other staff walk through the round

Other staff interrupt the round

Background conversation outside the round

Background conversation between people on the round

Desk phone

Mobile phone

Bleep

Alarm

Suction noise

Computer noise

Fire alarm

Power cut

Teaching during round

Social discussion during round

TV noise

Coffee machine noise

Ice maker noise

Washing (noise from sink) 